\section{EL PAPEL DE LAS EMOCIONES Y LA LITERATURA EN LA DELIBERACIÓN PÚBLICA: LA FIGURA DEL EQUILIBRIO PERCEPTIVO DE MARTHA C. NUSSBAUM}

\author{
Lidia de Tienda Palop \\ Universidad de Valencia \\ lidiadetienda@gmail.com
}

\begin{abstract}
Cómo citar este artículo/Citation: Tienda Palop, L. (2015). "El papel de las emociones y la literatura en la deliberación pública: la figura del equilibrio perceptivo de Martha C. Nussbaum". Arbor, 191 (773): a241. doi: http://dx.doi. org/10.3989/arbor.2015.773n3011
\end{abstract}

Recibido: 19 junio 2013. Aceptado: 4 marzo 2014

RESUMEN: El presente artículo sostiene que la literatura puede desempeñar un papel clave en los procesos de deliberación ética $y$, por tanto, se configura como una herramienta muy útil para la justificación y toma de decisiones de alcance público. Para apoyar esta tesis presento y examino la figura del equilibrio perceptivo propuesta por Martha Nussbaum, como método para canalizar los procesos de deliberación pública que integren las emociones en su propia estructura. Posteriormente analizo una de las posibles vías de aplicación del método propuesto: la introducción de los relatos narrativos, tanto históricos como ficcionales, en los planes de estudio como método para la deliberación ética.

PALABRAS CLAVE: Literatura; deliberación; imaginación pública; equilibrio perceptivo; Martha Nussbaum; emociones; educación.

\section{THE ROLE OF EMOTIONS AND LITERATURE IN PUBLIC DELIBERATION: THE FIGURE OF MARTHA C. NUSSBAUM'S PERCEPTIVE EQUILIBRIUM}

Copyright: (C) 2015 CSIC. Este es un artículo de acceso abierto distribuido bajo los términos de la licencia Creative Commons Attribution-Non Commercial (by-nc) Spain 3.0.

ABSTRACT: This article argues that literature can play a key role in the processes of ethical deliberation; therefore it can be regarded as an extremely useful tool to justify public decisionmaking. In order to support this thesis I examine Nussbaum's proposal of perceptive equilibrium as a method to conduct the public deliberation processes which integrates the emotions in its structure. Finally, I analyse one of the possible applications of the proposed method: introducing narrative texts, both historical and fictional, in the curricula as a method for ethical deliberation.

KEYWORDS: Literature; deliberation; public imagination; perceptive equilibrium; Martha Nussbaum; emotions; education. 


\section{LA CUESTIÓN DE LOS VALORES}

La alusión a valores en la vida pública es una constante. Se los nombra en los medios de comunicación, en los discursos políticos y en las conversaciones cotidianas de forma recurrente. Se habla de educar en valores, de respetarlos y se los señala como guía efectiva de las políticas públicas. Los valores se entiende que se encuentran a la base de una ciudadanía cívica y son considerados el presupuesto necesario para una sociedad democrática. Están presentes en la organización y estatutos de las empresas, en los preámbulos y exposición de motivos de las leyes e, incluso, en la motivación de las sentencias.

En principio la reivindicación de los valores no debería reducirse a una función meramente cosmética del discurso político porque la cuestión de los valores es de interés público: cuando los agentes sociales e institucionales competentes toman decisiones de ámbito público deben guiarse por los valores de forma real y efectiva para asegurarse legitimidad. Por tanto, es necesario preguntarse si los valores se encuentran verdaderamente integrados en la deliberación pública y, de igual manera, por el modo y los mecanismos previstos para que formen parte de la estructura institucional y la praxis pública. Con el fin de justificar si se encuentran presentes en la esfera pública, parece oportuno partir de una indagación teórica que determine su naturaleza y contenido sustantivo con el objetivo de extraer consecuencias pertinentes de alcance público. Sin embargo, cuando se habla de valores y se alude a ellos como idea regulativa, que guíe la deliberación pública y la consecuente praxis, emergen distintos problemas que convierten su utilidad, eficacia y función pública en una cuestión cuanto menos complicada.

En primer lugar, la controversia teórica entre las posiciones objetivistas y las subjetivistas en la concepción del valor dificulta su conceptualización y con ello su aplicación práctica. Diversos autores, en la línea de Scheler ${ }^{1}$ (2000), Hartmann (1949) u Ortega y Gasset (2006), conciben los valores como entidades cuasi-platónicas y, por tanto, objetivas. Estas posiciones sostienen que es posible encontrar un elenco cerrado de valores que actúe como criterio operativo de racionalidad moral. El acceso epistemológico a la esfera de valor, según estas posiciones, es fruto de un proceso de "desvelamiento" y su desconocimiento se debe al "error" o a la "ignorancia"2. Por otra parte, otros autores mantienen una posición subjetivista ${ }^{3}$, al concebirlos como entidades que operan en el ámbito psicológico del sujeto, motivo por el cual entienden que la articulación de una lista jerarquizada de valores es una cuestión difícilmente admisible.

Esta dualidad teórica en la concepción de la naturaleza del valor parece conducir a una aporía que imposibilita el objetivo propuesto de integrar de forma efectiva los valores en la praxis pública. Las posiciones objetivistas encuentran objeciones que ponen en duda la existencia de un catálogo de valores universal y esgrimen que estos valores corresponden a valores propios de una ideología, doctrina religiosa o posición comprehensiva particular. Por otra parte, las posiciones subjetivistas difícilmente pueden reclamar cierta universalidad en la justificación y fundamento de las decisiones fruto de la deliberación, lo cual dificulta el empleo de valores con carácter normativo.

El problema que plantea esta disyuntiva podría resumirse en esta pregunta: ¿Cómo articular el pluralismo y la normatividad para la utilización de los valores como guía de la praxis? En la base de esta pregunta se encuentra el problema clásico de cómo conjugar lo particular y lo universal, lo cual reviste una considerable complejidad teórico-práctica. En definitiva, la cuestión se resuelve en cómo incorporar los valores a la esfera pública evitando el conflicto y el desacuerdo a la vez que integrando el pluralismo en las propias estructuras deliberativas.

Las preguntas ¿Qué es un valor? o ¿Cuáles son los valores? difícilmente escapan a las objeciones mencionadas. Ambas cuestiones buscan un contenido material concreto o unas pautas prescriptivas determinadas, que garanticen un resultado cierto y seguro, pero con ello impiden la crítica y reflexión posterior y cierran la puerta al pluralismo, presupuesto ineludible de toda sociedad democrática. Sin embargo, si se evitan metodológicamente en el primer estadio de la reflexión estas cuestiones y se reformula la pregunta objeto de análisis del siguiente modo: ¿Cómo accedemos a los valores?, cambia la perspectiva de la indagación, lo cual permite elaborar una estrategia de aplicación práctica distinta para la deliberación de las cuestiones morales de interés público. La propuesta de deliberación pública que se sugiere se centraría en integrar en los procesos de deliberación los mecanismos por los cuales se accede a lo que se valora. La determinación del modo por el cual el ser humano capta los valores y la justificación de los mecanismos que habilitan su utilización práctica, posibilitaría la integración directa de los valores en los procesos de diseño institucional. Este enfoque evita el riesgo de prescriptivismo y de paternalismo, al eludir la aplicación directa de un código deontológico heterónomo. 
Lo que debe ser integrado en la deliberación pública no es un catálogo de valores en sí previamente elaborado, sino el dispositivo que nos permite acceder a lo que se valora. En este sentido, es necesario recordar que el objetivo de la deliberación no es la aplicación directa de un código normativo dado, sino la indagación de los medios óptimos para la consecución de un fin, que se ha deliberado previamente y que, en base a dichas elucidaciones, es considerado un bien (Aristóteles, 1999, pp. 1112a-1113a).

En esta línea de pensamiento se sitúa Martha Nussbaum que ha desarrollado una propuesta para la deliberación ética - aquella que versa sobre asuntos prácticos desde un punto de vista moral- susceptible de guiar la praxis pública, que, a su vez, integra los mecanismos que permiten la captación de los valores. La autora señala que las emociones son el dispositivo psicofísico con el que cuenta el ser humano para acceder a la esfera del valor y justifica que la literatura es un medio adecuado para la deliberación pública de cuestiones morales puesto que las incorpora en tales procesos de deliberación.

\section{LAS EMOCIONES COMO DISPOSITIVO DE PERCEP- CIÓN DE LOS VALORES}

Muchos autores clásicos y contemporáneos de diferentes disciplinas han argumentado que las emociones juegan un papel fundamental en la formación de los juicios morales y también en el modo en que los seres humanos realizan juicios de valor. Concretamente, en el campo de la filosofía, desde Aristóteles (1999), los Estoicos, en particular Crisipo (2006), Hume (1998), Hutcheson (1971), A. Smith (1997) o Scheler $(2000 ; 2001)$ hasta autores más contemporáneos como de Sousa (1987) o Nussbaum (2008), entre otros, atribuyen una función evaluativo-cognitiva a las emociones.

Scheler, que es el autor clásico de referencia en el ámbito de la teoría de los valores, señala que las emociones funcionan como intuiciones primarias en la aprehensión de valores (Scheler, 2001, pp. 361-363). Sus obras ofrecen un estudio riguroso y sistemático en torno a la cuestión del valor y desarrollan extensamente el modo de captación de los valores. Sus tesis se articulan en torno a un conjunto de tratados que se podrían calificar globalmente de fenomenología de la emoción, puesto que el método que se encuentra en la base de sus escritos es el fenomenológico y, además, otorga un papel privilegiado a las emociones en la epistemología axiológica. Al examinar la vía de acceso a los valores y, por tanto, cómo son dados a la conciencia, Scheler advierte que la facultad que permite la aprehensión de los mismos no es la pura percepción intelectual, sino que los valores son captados por el sentir intencional, que descansa en el percibir sentimental en un sentido primario (Scheler, 2001, pp. 356-369). Esta facultad, que posibilita la intuición primaria de captación de los valores, implica un conocimiento intencional sentido de aquello que es inmediatamente aprehendido: el valor. Este sentir intencional se estructura en torno a un componente intencional y uno emocional (Scheler, 2001, p. 361). La intencionalidad hunde sus raíces en la noción de intentio, central en las tesis de Brentano. Brentano desarrolló el concepto de intencionalidad en 1874 (Brentano, 1874) e influyó de manera decisiva en la fenomenología de Husserl y, por tanto, en la obra de Scheler. La idea fundamental del término intencional se incardina en tono a la noción del cogito cartesiano, puntualizando que el cogito es siempre un cogito cogitatum. La intencionalidad es ese "dirigirse a" de la conciencia, por la que el objeto le es dado. Pero, además, según Scheler, la percepción intencional de los valores es sentimental $y$, de este modo, las emociones adquieren una función cognitiva fundamental: nos permiten el acceso al mundo de los valores. Las emociones en la teoría de Scheler operan como intuiciones primeras de lo que es valioso y, por tanto, proporcionan el tipo de cognición requerida para la aprehensión primaria de los valores (Scheler, 2001, pp. 361-363).

Otros autores contemporáneos, que se han dedicado de forma sistemática al estudio de las emociones, sostienen que estas son racionales y, por tanto, consideran que no son puros actos somáticos, poniendo en cuestión la tesis principal del polémico artículo de James "What is an emotion" (James, 1884). James revolucionó el ámbito científico del estudio de las emociones atribuyéndoles una base exclusivamente fisiológica. Sin embargo, autores como Ronald de Sousa (1987) y Martha Nussbaum (2006; 2008) adscriben a las emociones una función cognitiva concreta en virtud de la cual se desencadenan. Las emociones se diferencian de los estados fisiológicos o de los apetitos de algún modo. No es lo mismo tener hambre que sentir alegría, mientras que la sensación de hambre referiría a cierto estado fisiológico apetitivo reflejo, la alegría precisa de una complejidad psicológica considerable en la que media un componente mental sofisticado. La respuesta emocional se suscita solamente si se concede a las emociones una función cognitiva dirigida a proporcionar al sujeto una ampliación experiencial a partir del conocimiento del objeto susceptible de afectar al sujeto emocional. Para que 
las emociones se actualicen se requiere que en tal sujeto, capaz de experimentar emociones, opere una estructura evaluativa que le permita ponderar, priorizar y jerarquizar según un concepto particular de interés que subyace a toda emoción. En este sentido de Sousa vincula de manera directa las emociones con las creencias y con los objetos intencionales (Sousa, 1987, pp. 116-117) y Nussbaum les concede una estructura cognitivo-evaluativa básica que sistematiza en su obra Paisajes del pensamiento: la inteligencia de las emociones (Nussbaum, 2008).

\subsection{La naturaleza cognitiva-evaluativa de las emo- ciones en el pensamiento de Martha Nussbaum}

Entre las múltiples definiciones de lo que son las emociones, que Nussbaum proporciona en sus estudios, destaca por su claridad gráfica la que da título a su obra sistemática sobre la materia por la que considera que las emociones son "levantamientos geológicos del pensamiento" (Nussbaum, 2008, p. 21). Esta expresión da cuenta tanto de la dimensión fisiológica como cognitiva, que se encuentra a la base de las emociones, pero, además, esta fórmula de raigambre proustiana (Nussbaum, 2008, p. 85) posee una viveza expresiva peculiar, puesto que deja entrever un elemento, que no es ni el corporal, ni el mental, sino aquél que precisamente aporta la fuerza a la definición: el componente motivacional. Para que se produzcan tales levantamientos del pensamiento es necesario que medie algún tipo de circunstancia que produzca semejantes alteraciones psicosomáticas denominadas emociones. Nussbaum considera que aquello que es susceptible de motivar una reacción emocional posee una íntima vinculación con la esfera de valor que opera en el ámbito íntimo del sujeto. Las emociones se configuran como aquellos "pensamientos acerca del valor y la importancia que hacen que la mente se proyecte al exterior como una cadena montañosa, en lugar de permanecer inmóvil e inerte, cómodamente satisfecha de sí misma" (Nussbaum, 2008 , p. 21). De este modo, la autora reformula su expresión metafórica inicial de la emoción como "respuesta inteligente a la percepción del valor" (Nussbaum, 2008, p. 21). Esta definición precisa de forma clara que las emociones son, en definitiva, formas de conocimiento, en tanto que son perceptoras y lo son de una percepción muy particular. Aquello que es percibido, si es susceptible de desencadenar una emoción, debe vincularse de una forma concreta con la esfera íntima de valor del sujeto. Por tanto, las emociones poseen una función cognitiva que determina qué es lo que el sujeto emocional valora.
Esta tesis, que pudiere parecer novedosa, en realidad, es heredada de la tradición estoica. La autora toma prestada la concepción que los estoicos clásicos sostienen acerca de las emociones para su propia teoría, a la que califica de neoestoica, reformulando algunos de los presupuestos de estos autores clásicos, con el fin de resolver determinados problemas que impiden utilizar a las emociones con fines éticos. Partiendo de la definición que atribuye directamente al planteamiento estoico, afirma que las emociones son "evaluaciones o juicios de valor, que atribuyen a las cosas y a las personas que están fuera del control de esa persona una gran importancia para el florecimiento de la misma" (Nussbaum, 2008, p. 24 y p. 44). A partir de estas premisas estoicas Nussbaum precisa tres componentes de la emoción que determinan y configuran su estructura cognitivo-evaluativa (Nussbaum, 2008, p. 24):

\section{a) La idea de valoración cognitiva}

La "valoración cognitiva" es el elemento crucial para que una emoción se suscite. En el caso de que no exista una percepción de valor, la emoción no tendrá lugar. Las emociones, de este modo, informan sobre aquello que es valioso para el sujeto y por ello poseen una función "cognitivo-evaluativa" (Nussbaum, 2008, p. 45). El término "cognitivo" es utilizado en este contexto para expresar exclusivamente aquello "relativo a la recepción y al procesamiento de información" y no se refiere, por tanto, ni a "cálculo elaborado" ni a "autoconciencia reflexiva" (Nussbaum, 2008, p. 45). Sin embargo, para que una emoción se suscite, esta función "cognitiva" de las emociones debe ser, a su vez, "evaluativa": la cognición se encuentra formalmente investida de valor. El concepto "evaluativo" supone la combinación de la percepción de un objeto y el pensamiento acerca de su relevancia e importancia para el sujeto, de modo que el contenido cognitivo que las emociones proporcionan es un contenido intencionalevaluativo acerca de lo que el sujeto valora.

\section{b) La idea del propio florecimiento}

La naturaleza evaluativa de la cognición propia de las emociones, que hace referencia a la importancia del objeto intencional para el sujeto emocional, introduce la dimensión subjetiva del interés en la concepción del objeto. El carácter subjetivo de la percepción del objeto, capaz de provocar la emoción en un sujeto, no se circunscribe únicamente a la relación noemática entre el sujeto y el objeto fenomenológicamente aprehendido $y$, por tanto, no se reduce a un mero "darse a la conciencia". Precisamente, sus conexiones 
con la dimensión subjetiva del sujeto emocionalmente afectado tienen un calado más amplio y profundo. En otras palabras, dicha percepción precisa de cierto acto vinculativo con la globalidad de la esfera íntima y subjetiva del sujeto para que pueda surgir la emoción.

Nussbaum, en este extremo, señala que el acto de aprehensión evaluativa del objeto, que realiza el sujeto emocionalmente afectado, debe relacionarse de forma efectiva con la esfera del bienestar del sujeto para que se suscite la emoción. De este modo, el contenido cognitivo-evaluativo percibido en la emoción se encuentra modulado por la contribución del objeto valioso al bienestar del ser perceptor. Por tanto, las emociones poseen un componente que la autora denomina eudaimonista. Este carácter eudaimonista, que dirige la valoración, permite, por una parte, conectar los estados emocionales con las esferas subjetivas de valor, al remitir a los proyectos vitales íntimos, pero también con cierta noción última de "florecimiento" que el sujeto alberga (Nussbaum, 2008 , p. 54) y, por tanto, lo vincula con una cosmovisión universal de la vida. En consecuencia, la emoción es "idéntica a la aceptación de una proposición a la vez evaluadora y eudaimonista, esto es, concerniente a uno o más de los objetivos y fines importantes de la persona" (Nussbaum, 2008, p. 64) en particular y del ser humano en general.

\section{c) La relevancia de los objetos externos}

Tras precisar la particular vinculación existente entre la emoción y los objetos externos, al señalar que estos objetos se presentan a la percepción como investidos de valor, es oportuno explicar el porqué de su importancia para el sujeto. La relevancia que determinados objetos poseen para el sujeto radica precisamente en su carácter de ser externos. El concepto de externalidad en el pensamiento de Nussbaum posee un significado peculiar, de tradición estoica, que refiere a la influencia de los objetos externos en las reacciones del sujeto. El contenido semántico de lo "externo" en relación a los objetos, en este contexto, no remitiría al hecho de encontrarse "fuera" de la esfera corporal de la persona, sino que "externo" hace referencia a que quedan fuera del control completo y absoluto de la persona (Nussbaum, 2008, p. 64). Esta apreciación se encuentra en la base del propósito estoico de extirpar las pasiones, puesto que, en definitiva, el concepto de externalidad le recuerda al ser humano su condición de finitud y su naturaleza vulnerable. De hecho, las cosas vulnerables son aquéllas que "pueden verse afectadas por eventos del mundo que se hallan fuera del control de la persona, que pueden llegar por sor- presa, que pueden ser destruidas o eliminadas incluso cuando uno no lo desea" (Nussbaum, 2008, p. 54). Sin embargo, hemos de señalar que precisamente esa vulnerabilidad innata a la que está sometida el ser humano es la que le urge a valorar: solamente mediante el continuo ejercicio de valoración y ponderación el ser humano finito puede garantizarse su supervivencia y viabilidad en su interacción con el medio. En este sentido, Nussbaum sostiene que "la emoción registra esa sensación de vulnerabilidad y de control imperfecto" (Nussbaum, 2008, p. 66) y la autora perfila más profundamente la noción de emoción en otras de sus obras, al concebirlas como "respuestas a estas áreas de vulnerabilidad, en las que registramos los perjuicios que sufrimos, que podríamos sufrir o que por suerte no padecemos" (Nussbaum, 2006, p. 19).

\subsection{La función epistemológica de las emociones}

Los tres elementos precisados configuran una estructura formal valorativa de la emoción. Dependiendo de las peculiares características sustantivas de estos componentes -que la información afecte negativamente al bienestar del sujeto o que el valor del objeto se conciba como menos relevante por ejemplo-se originarán unas emociones u otras, pero formalmente estos tres elementos de naturaleza valorativa poseen un carácter constitutivo y necesario en todas y cada una de las emociones. Por otra parte, los tres componentes poseen una referencia a la dimensión subjetiva, en tanto que en los tres es necesario que medie un factor clave de carácter evaluativo. Ninguno posee un carácter objetivo independiente del sujeto, por el contrario su configuración objetiva viene determinada por sus características objetivas formales junto con un componente subjetivo sustantivo: el objeto propio de los tres elementos apuntados es un objeto configurado según la particular dimensión subjetiva del sujeto afectado por una emoción. Esta característica posee una importancia capital para la viabilidad psicofísica y supervivencia del sujeto emocional y desvela la importancia y significado de la función y estructura cognitivo-evaluativa de las emociones.

Como se ha apuntado, las emociones proporcionan un tipo de cognición peculiar, que no se circunscribe únicamente a la información cognitivo-sensorial aportada por la percepción, sino que la naturaleza de la información recibida es más compleja en tanto que es de carácter valorativo. Esta circunstancia permite inferir ciertas conclusiones que poseen consecuencias prácticas valiosas para los fines de la deliberación ética. Por una parte, en virtud del carácter íntimamente 
subjetivo que opera en la información cognitiva suministrada por las emociones es posible fundamentar un determinado tipo de conocimiento de carácter introspectivo, que informe acerca de la dimensión subjetiva $y$, por otro lado, la estructura valorativa de las emociones proporciona una vía de acceso a la esfera del valor, en tanto que indican aquello que resulta valioso para el sujeto emocional. Dicho en otras palabras: las emociones son la herramienta mediante la cual el sujeto percibe los valores.

Esta afirmación requiere de una precisión conceptual ulterior para comprender su verdadero alcance y las posibilidades del empleo de las emociones en la deliberación de cuestiones prácticas. Las emociones son perceptoras de valor en un sentido primario y, por ello, poseen la característica apuntada por los estoicos de "frescura" necesariamente, en tanto que se constituyen como reacciones inmediatas a la percepción de valor. Por ello, el acto valorativo que tiene lugar cuando surge una emoción no es de la misma índole que la acción de "valorar" que se da comúnmente en los ejercicios deliberativos. Esta última más bien tendría que ver con la ponderación y el cálculo. El razonamiento deliberativo se encuentra en un nivel distinto al de las emociones. Las emociones pierden intensidad en el transcurso temporal desde la percepción del objeto y la deliberación y el cálculo deben ser posteriores para que puedan ser guiadas con la serenidad de ánimo necesario, de la que carecen las emociones, sin perder, no obstante, de vista la valiosa información suministrada por la reacción emocional.

Tras justificar que las emociones son el dispositivo psicofísico con el que está dotado el ser humano para la captación de los valores, nos encontramos en un segundo estadio de la reflexión: la incorporación de las emociones a la deliberación ética que guíe la praxis pública. Como se ha observado, el acto de percepción de los valores depende de un ejercicio introspectivo, llevado a cabo por el sujeto emocional y, por tanto, la captación de los valores queda vinculada a la dimensión subjetiva del sujeto perceptor, con lo cual parece que el mundo de los valores no puede entenderse si no es en relación al mundo subjetivo de los valores. Como resulta evidente, esta consideración complica mucho la cuestión de si es posible entonces, a partir de una teoría de las emociones, encontrar en los juicios emocionales-valorativos la forma del juicio ético, en tanto que este exige ser universalizable para constituirse como tal. Por ello, es necesario indagar qué mecanismos de deliberación se pueden encontrar para incluir a las emociones en la deliberación ética, que no se limiten a una mera exposición de intereses y objetivos particulares, sino que trasciendan el ámbito de la pura subjetividad y sirvan para asesorar acerca de los fines universales. En esta línea, Nussbaum ha propuesto la utilización de la imaginación pública como metodología deliberativa mediante la figura del equilibrio perceptivo para este fin.

\section{EL PAPEL DE LAS EMOCIONES EN LA DELIBERACIÓN ÉTICA: EL MÉTODO DEL EQUILIBRIO PERCEPTIVO DE MARTHA NUSSBAUM}

Los estudios sistemáticos acerca de la naturaleza de las emociones de Nussbaum poseen un objetivo último de calado ético. Además de estudiar y sacar a la luz la importancia para el ámbito de la ética que poseen las emociones, la autora a lo largo de sus obras propone una metodología deliberativa que las incorpora en su misma estructura. El objetivo de Nussbaum es posibilitar la integración de las emociones en una teoría de la justicia que pueda dar respuesta a urgentes problemas de justicia no resueltos y determinar la importancia de su participación directa en los procesos de deliberación pública. De este modo, la autora propone el método que bautiza como equilibrio perceptivo, que se configura como un una forma novedosa de articular un mecanismo de aplicación, basado en el "método del silogismo práctico" aristotélico, para la deliberación pública que además otorga a las emociones un papel destacado en el proceso de desvelamiento de los juicios éticos.

\subsection{El equilibrio perceptivo y la deliberación ética}

Nussbaum elabora una propuesta metodológica para la deliberación ética -aquella que se ocupa de las cuestiones prácticas- que permite la incorporación de las emociones en una metodología deliberativa denominada equilibrio perceptivo. Esta figura posee ciertos paralelismos con el conocido método del equilibrio reflexivo ${ }^{4}$, acuñado y profusamente utilizado por Rawls para la elaboración de su Teoría de la Justicia, pero también entraña sutiles diferencias que resultan valiosas para la formulación de una propuesta alternativa a la rawlsiana.

En el método del equilibrio perceptivo de Nussbaum confluyen diferentes elementos de la teoría deliberativa aristotélica, siendo el concepto

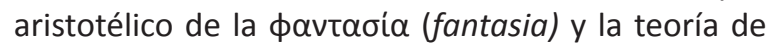
la acción del Estagirita ${ }^{5}$ centrales en la configuración de dicho método. De hecho, todos los elementos de la teoría ética aristotélica concurren en la figura del 
equilibrio perceptivo y proporcionan las herramientas conceptuales necesarias para articular una propuesta de fundamentación y método práctico para la deliberación ética que integra las emociones en su propia estructura.

Nussbaum señala que el procedimiento que se lleva a cabo en el equilibrio perceptivo es "un diálogo reflexivo entre las intuiciones y creencias del interlocutor o lector y una serie de concepciones éticas complejas, que se proponen para su estudio. (En opinión de Aristóteles, lo ideal sería considerar las opiniones tanto de "los sabios" como de la "mayoría")" (Nussbaum, 1995a, p. 39). La propia Nussbaum cita las palabras de Aritóteles en la Ética a Nicómaco cuando indica que estas intuiciones y creencias, que se constituyen en el objeto específico de la investigación ética, puesto que a partir de ellas se procederá a la efectiva elaboración de la propuesta ética concreta, susceptible de ser llevada al campo de la praxis, corresponden a "los valores y juicios de individuos que han determinado previamente sus apegos e intuiciones (Nussbaum, 1995a, p. 39). Por tanto, el resultado de esta actividad deliberativa no es el simple consenso de voluntades individuales agregadas, sino que el proceso de introspección y elaboración de los juicios de valor llevado a cabo se realiza de forma compleja.

El ejercicio deliberativo que se realiza mediante la figura del equilibrio perceptivo requiere cierta labor "transformativa" de los sujetos participantes en la deliberación, condicionada por una actitud de apertura emocional. De este modo, Nussbaum exige que "los interlocutores o lectores se hayan convertido en cierto tipo de personas" (Nussbaum, 1995a, p. 39) para que la deliberación ética pueda llevarse a cabo de forma correcta. Por consiguiente, el resultado de la deliberación ética no puede limitarse a una mera repetición de las concepciones del sujeto, tal y como este las formularía en un principio, sino después de haber realizado ciertos ejercicios introspectivos para acceder a la esfera de valor mediante la indagación emocional. Con el fin de hacer valer estos requisitos metodológicos, Nussbaum recoge una observación de Aristóteles, por la que el Estagirita subraya -tal como hizo Sócrates antes que élque la mayoría de las personas, cuando se les pide una generalización, realizan afirmaciones que no hacen justicia a la complejidad y el contenido de sus verdaderas opiniones. Necesitan, pues, descubrir lo que realmente piensan. Para ello, deben realizar "un ajuste armonioso de sus opiniones, individual y colectivamente" recurriendo a "la reflexión y el diálogo con los demás"; pero además este diálogo debe profundizar en la psique emocional para poder acceder a la esfera del valor. Una vez realizado este proceso "se habrá alcanzado la verdad ética, según entiende Aristóteles la verdad en general: verdad antropocéntrica, pero no relativista" (Nussbaum, 1995a, p. 39). La autora, consciente de las dificultades prácticas de este modo de proceder, asume el componente intrínseco de indeterminación y carácter incompleto de su propuesta reconociendo que "en la práctica, la búsqueda raras veces llega a su término o es lo bastante completa; así pues, el resultado será solo el mejor candidato actual a la verdad" (Nussbaum, 1995a, p. 39).

Este proceso deliberativo se encuentra dirigido por "el principio de no contradicción" aristotélico, que aporta las garantías de corrección indispensables en el procedimiento de resolución de los problemas prácticos. Este principio se basa en una intuición básica de la razón, que se configura como criterio de racionalidad: la búsqueda de coherencia. Esta noción de coherencia, que opera en el ámbito práctico, no es un mero presupuesto lógico-formal propio de los saberes deductivos, sino que lo que pretende es la coherencia interna del razonamiento. La búsqueda de la verdad coherente, del ajuste armonioso entre las premisas y los objetivos prácticos, debe regresar continuamente a los fenómenos para validarse. Por tanto, "la teoría no debe abandonar su compromiso con los modos en que los seres humanos viven, actúan y ven, esto es, con los pragmata entendidos en sentido amplio" (Nussbaum, 1995a, p. 324). De este modo, la teoría ética debe ser pragmática.

El método que sigue este proceso se estructura en torno a tres operaciones: a) reflexión y diálogo b) ajuste y c) desvelamiento, que no se realizan secuencialmente, sino simultáneamente en un mismo acto. Para que se inicie el proceso deliberativo, es necesario que los sujetos participantes partan de unas percepciones cognitivas peculiares. Estas percepciones son el resultado de las intuiciones originales acerca de los juicios valorativos de los agentes perceptores, alcanzado tras un proceso de "desvelamiento" de carácter emocional, el cual no se da de forma inmediata, sino que es producto de un "ajuste" armonioso tras un proceso reflexivo y de diálogo. Nussbaum propone la utilización de la literatura para poder llevar a cabo estos procesos, aportando con ello una fórmula novedosa y con enormes potencialidades para la deliberación ética de los asuntos prácticos. 
3.2. El recurso a la imaginación literaria como método para incorporar a las emociones en la deliberación ética

Nussbaum propone utilizar la literatura como método para llevar a cabo el proceso de "desvelamiento" mencionado y para canalizar la deliberación ética sobre asuntos prácticos y, de esta forma, alcanzar el "ajuste" pretendido. La razón que le lleva a la autora a recurrir a la ficción narrativa como instrumento de deliberación y, por tanto, a no limitarse a señalar determinadas condiciones para un diálogo participativo, es básicamente que el objetivo del equilibrio perceptivo no es lograr la mera suma de voluntades individuales que puedan llegar a acuerdos fácticos, sino la fundamentación de una propuesta sustantiva que pueda alcanzar un consenso suficientemente universal que verdaderamente integre el evidente pluralismo de la realidad humana. El resultado del equilibrio perceptivo no surge de una suerte de balance entre opiniones particulares, sino de los juicios elaborados y complejos de los sujetos participantes que, a su vez, son "agentes perceptores", puesto que se han sometido a un acto transformativo para profundizar en su intimidad emocional y percibir de forma clara y distinta aquello que valoran. Para ello propone la utilización de las narraciones ficcionales, especialmente las tragedias (Nussbaum, 1986, pp. 233-267) y las novelas (Nussbaum, 1983; 1990; 1991; 1995a; 1997), por considerar que ofrecen magníficas posibilidades deliberativas. En este sentido afirma que "para pasar de la opinión a la teoría, a menudo se considera útil trabajar con los textos, orientando al interlocutor en la elucidación y valoración de la postura compleja de otra persona (o, mejor, de varias posturas distintas) sobre un problema determinado. Ello permite un cierto distanciamiento con respecto a los propios prejuicios teóricos. Además, si la selección de textos es lo bastante cuidadosa podremos confiar en haber examinado las principales posibilidades" (Nussbaum, 1995a, p. 39).

\section{EL PAPEL DE LA LITERATURA EN LA DELIBERACIÓN ÉTICA}

En los apartados precedentes se ha precisado la importancia fundamental que poseen las emociones para la ética, en tanto que se configuran como el dispositivo psicofísico de captación de los valores. Por esta razón parece pertinente proceder a una búsqueda y justificación de los medios adecuados para que adquirieran un papel significativo en la esfera pública y en el desarrollo de las políticas públicas. Precisamente con este fin Nussbaum propone la utilización de la imaginación literaria en los procesos de deliberación pública, primordialmente porque considera que es el método más adecuado para incorporar a las emociones en dicha deliberación ética de alcance público.

\subsection{Ficción literaria y deliberación pública}

El objetivo de incorporar la literatura como instrumento para los procesos de deliberación pública resulta algo insólito en el panorama contemporáneo de la filosofía política y del derecho. De hecho, son numerosas las críticas que se muestran contrarias a otorgar credibilidad a los argumentos basados en ficciones narrativas. Determinadas posiciones, en la línea de las tesis de Posner (1981) y el movimiento americano Law and Economics, sostienen que la literatura debe permanecer confinada al espacio lúdico privado. Estas corrientes de pensamiento consideran que la característica peculiar que identifica un relato ficticio es que es ideal y por ello infieren que no puede servir de ayuda en las cuestiones prácticas relacionadas con las circunstancias reales y fácticas (Nussbaum, 1991, p. 880). Pese a ello, Nussbaum sostiene de forma explícita no solo que la literatura puede contribuir a la esfera pública, sino que desempeña una función capital e imprescindible en los procesos de deliberación ética.

La práctica actual, generalizada y comúnmente aceptada en la mayoría de las disciplinas del ámbito de las ciencias sociales, es la utilización de informes y estudios elaborados a partir de datos estadísticos para la justificación de las decisiones en materia de políticas públicas y validación del consiguiente diseño institucional. Aunque Nussbaum no propone eliminar totalmente la herramienta de la estadística y otras metodologías similares de operacionalización, sí que subraya que incluso en las cuestiones relacionadas con la medición del bienestar de la población, la literatura desempeña un rol fundamental y necesario en la captación de lo que es valioso y por tanto merecedor de protección. En este sentido se pregunta "qué actividades de la personalidad son las mejores para esta tarea, qué pensamientos, qué sentimientos y qué modos de percibir" (Nussbaum, 1991, p. 880).

Nussbaum ilustra su argumento mediante la novela Tiempos Dificiles, en la que la estadística es empleada no solo como un recurso para escribir informes cuantitativos, sino como el medio específico para tratar con las personas en los encuentros cotidianos. A menudo, este modo de proceder, basado exclusivamente en parámetros cuantitativos y medibles, reclama para sí el estatuto de "criterio de racionalidad" o de única justificación racional y se extralimita en su 
objetivo original de servir como una útil y manejable herramienta profesional, para convertirse en una verdadera norma y criterio de legitimación excluyente (Nussbaum, 1991, p. 881), con todos los peligros que ello conlleva. A pesar de que se pueda justificar esta práctica generalizada en la pretensión de estos métodos de alcanzar seguridad, certeza y exactitud en las conclusiones teóricas y prácticas debido a su naturaleza cuantitativa, no es menos cierto que cuando se piden razones, fundamentos o motivos que legitimen una determinada praxis, estas metodologías se muestran incompletas y no satisfacen suficientemente los requisitos de una explicación solvente.

Sin embargo la utilización de las ficciones narrativas bien puede constituirse en un instrumento apropiado para la deliberación ética y, por tanto, pueden convertirse en una herramienta de utilidad pública. En concreto, Nussbaum sostiene que la novela es un género literario muy adecuado para deliberar sobre determinados problemas prácticos, puesto que como argumenta, parafraseando a Aristóteles, "el arte literario es más filosófico que la historia, porque la historia se limita a mostrar "qué sucedió", mientras que las obras literarias nos muestran "las cosas tal como podrían suceder" en la vida humana" (Nussbaum, 1997, p. 29). La novela es el género literario que la autora considera más adecuado para la deliberación ética porque permite la puesta en marcha del mecanismo de la imaginación empática, ya que se dirige a la suscitación de las emociones en el lector. En este sentido diverge de otros géneros como la historia o las biografías, que, por otra parte, pueden también ser muy valiosas, pero lo son de distinto modo. En principio estos otros géneros tienen valor a nivel informativo, sin embargo, en la medida en que son capaces de suscitar emociones, observamos que se asemejan más al género literario. Por otro lado, la poesía o la música sí que poseen un potencial innegable como generadoras de emociones, pero, por otra parte, carecen del elemento narrativo, que sí que se halla en la novela y en otros géneros como el teatro o los relatos cortos. No obstante, "las obras musicales más serias poseen un contenido emocional expresivo en algunos casos (las sinfonías de Mahler o el jazz, por ejemplo) y es natural pensar que ese contenido se desarrolla en forma narrativa, aunque también sabemos que toda representación verbal de esa narración es a lo sumo una tambaleante traducción" (Nussbaum, 1997, p. 31). Si bien Nussbaum ha señalado la utilidad para la deliberación ética de otros géneros de relato ficcional como son las tragedias, los relatos cortos o incluso el cine, la autora otorga un papel privilegiado a la novela para este fin. La novela transporta a la imaginación a través de un proceso: "este movimiento complejo de la imaginación y la razón, de lo concreto a lo general y de nuevo a lo concreto, a través tanto de la simpatía y la identificación" (Nussbaum, 1991, p. 903).

Nussbaum considera que la novela, pese a ser una "figura moralmente controvertida, expresa, con su forma y estilo, en sus modalidades de interacción con los lectores, un sentido normativo de la vida. Pide a sus lectores que observen esto y no aquello, que actúen de tales maneras y no de otras. Los induce a adoptar ciertas actitudes en vez de otras, con la mente y el corazón" (Nussbaum, 1997, p. 26). Con esta observación, la autora fundamenta el valor y dimensión ética singular de este género literario.

Al afirmar que la novela desempeña una función ética, podría darse a entender que Nussbaum está sugiriendo en realidad que la literatura posee una función pedagógica: la de enseñar "formas de vida buena" y, por tanto, inculcar en los lectores unos hábitos correctos que guíen su conducta, con el fin de producir "ciudadanos buenos" en lugar de "buenos ciudadanos". Si dicha función ética supusiera toda una paideia, entonces podría reconocerse cierta perversión en sus propósitos éticos. La novela, en este sentido, al utilizarse con fines éticos se transformaría en un mecanismo de "adoctrinamiento" de la ciudadanía y difícilmente podría hacer frente a las críticas de parcialidad, prescriptivismo y paternalismo en sus enseñanzas. Ciertamente el papel normativo en la vida pública no puede -ni debe- descansar en las novelas. La novela cuenta historias, se incardina en un suelo físico, se adhiere a un punto de vista concreto, huye de la abstracción y rescata la particularidad. Y es precisamente ahí donde reside su virtud y su vicio.

La literatura no es solo sumamente subjetiva, sino que es absolutamente parcial. Se posiciona en una perspectiva determinada y cuenta la historia única de su coherencia. La importancia ética de la novela estriba precisamente en el hecho de que cuenta una historia: una, no toda la historia. Es parcial, pero en su particularidad reside su poder hechizante y embriagador. Lo que genera en el lector no es un razonamiento abstracto, para una comprensión lógica y causal de los acontecimientos. La novela que solo produce eso es una mala novela, difícil de digerir, que pronto se olvidará. Una buena novela provoca emociones en el lector. Una buena novela: apasiona. Si es muy buena, la pasión se torna en obsesión, eliminando cualquier vestigio de sueño. Un lector apasionado es un lector ojeroso. ¿Cómo es que produce eso? Pues solo 
su defecto constitutivo, que es la parcialidad, puede suscitar semejantes reacciones. Y lo hace porque la literatura pone en funcionamiento el maravilloso mecanismo de la imaginación.

La imaginación posee una estructura indispensable en toda deliberación ética: permite la representación de la externalidad, de lo otro. Solo mediante ejercicios empáticos es posible incorporar la experiencia del otro y, por tanto, encontrar elementos vinculantes. "A diferencia de la mayoría de las obras históricas, las obras literarias invitan a los lectores a ponerse en el lugar de personas muy diversas y a adquirir sus experiencias" (Nussbaum, 1997, p. 30). Ahora bien, esta comprensión del "otro" mediante la literatura no solamente se produce a un nivel lógico, sino que esta comprensión es emocional y, por tanto, lo que genera no son meros juicios proposicionales, sino evaluaciones que son propias de los juicios éticos.

La literatura al permitirnos mediante el recurso de la imaginación conectar con la experiencia particular de la alteridad y producir comprensión emocional, bien sea sintonizando con los personajes o en manifiesto desacuerdo, posee una fuerza motivacional única. Alienta, inspira y motiva la reflexión: calienta sus motores y le aporta la energía necesaria para su despegue. "En su misma forma de interpelar al lector hipotético, transmiten la sensación de ser eslabones de posibilidad, al menos en un nivel muy general...en consecuencia, activan las emociones y la imaginación del lector" (Nussbaum, 1997, p. 30) y ello posee relevancia para el pensamiento público. Por eso, el proyecto de Nussbaum no se dirige a una recopilación de "doctrina ética" proporcionada por las novelas, sino que su objetivo es más profundo, ${ }^{6}$ puesto que se pregunta qué clase de sentimiento e imaginación cobran existencia cuando el texto interpela a sus lectores hipotéticos, qué clase de actividad desencadena la lectura (Nussbaum, 1997, p. 28).

Por ello la autora sostiene que "la buena literatura es perturbadora de una manera en que rara vez lo son la historia y las ciencias sociales. Como suscita emociones poderosas, desconcierta e intriga. Inspira desconfianza por la sensiblería convencional y provoca una confrontación a menudo dolorosa con nuestros pensamientos e intenciones. Podemos enterarnos de muchas cosas sobre la gente de nuestra sociedad y sin embargo mantener ese conocimiento a distancia. Las obras literarias que promueven la identificación y la reacción emocional derriban esas estratagemas de autoprotección, nos obligan a ver de cerca muchas cosas que pueden ser dolorosas de enfrentar y vuelven digerible este proceso al brindarnos placer en el acto mismo del enfrentamiento" (Nussbaum, 1997, p. 30). Por otra parte, la autora también sostiene que el juego entre lo general y lo concreto "forma parte de la estructura misma del género, de su manera de interpelar a los lectores. La novela construye un paradigma de un estilo de razonamiento ético que es específico al contexto sin ser relativista, en el que obtenemos recetas concretas y potencialmente universales al presenciar una idea general de la realización humana en una situación concreta, a la que se nos invita a entrar mediante la imaginación. Es una forma valiosa de razonamiento público, tanto desde una perspectiva intracultural como desde una intercultural" (Nussbaum, 1997, p. 33).

\subsection{La importancia del lector como agente perceptivo}

Si bien la literatura posee una relevancia fundamental como instrumento de deliberación pública, la figura que permite con su imaginación que las narraciones cobren vida es el lector. El lector, en su actividad de lectura, pasa por un proceso: "se involucra con los personajes, se preocupa por sus proyectos, sus esperanzas y sus miedos, participa en sus intentos de desentrañar los misterios y perplejidades de sus vidas" (Nussbaum, 1991, p. 891). Por tanto lleva a cabo una participación activa que posibilita la efectiva actualización de la novela y que desemboca en dos hechos: el lector se ve afectado emocionalmente por los acontecimientos narrados y realiza una continua actividad crítica y evaluativa de la acción relatada. De manera que el "lector" es un sujeto marcado por una doble faceta: es un sujeto afectado y, además, es un sujeto perceptivo.

El lector es un sujeto perceptivo porque su actividad es precisamente la de conocer y penetrar en las esferas particulares de otros mundos distintos al suyo. De este modo, con la narración se le abre un "mundo de posibilidades" que en conjunción con su otra dimensión de "ser afectado", y por ello parte activa y subjetivamente implicada, le brinda la oportunidad de crear su propio espacio de acción y de deliberación particular. El lector percibe una historia particular que, cuando es comprendida, pasa a ser internalizada y se convierte en propia, contribuyendo a la configuración de su propia deliberación y juicio personal. El lector, al verse afectado emocionalmente, participa activamente en la narración y vuelve la vista no a una historia particular separada, sino a una historia que se rela- 
ciona con la suya propia, lo cual genera vínculos de comunidad. La reflexión que surge de esta actividad ya no es una deliberación parcial y particularmente interesada, sino una deliberación que abarca las múltiples posibilidades de la vida humana. Los lectores son agentes perceptivos porque se trata de sujetos que son a la vez perceptivos y afectados. Son sujetos que se encuentran en posición de llevar a cabo con éxito las deliberaciones propias del equilibrio perceptivo.

En consecuencia, las novelas representan un excelente mecanismo para integrar la dimensión ética en los procesos de deliberación pública, puesto que invitan a los lectores a ser afectados por los destinos de los demás, como si fueran los propios, vinculándose mediante la amistad simpatética y la identificación empática. Cuando al lector se le interpela de este modo, su respuesta natural, si ha "leído bien", debería ser una respuesta que tomara conciencia de la situación de los pobres y desfavorecidos como si fuera propia (Nussbaum, 1991, p. 894). Para ello es necesaria cierta actitud del lector, cierta predisposición a querer "leer en serio". Mediante esta figura del "leer en serio" o "leer bien" (reading well) Nussbaum no se está refiriendo a leer acorde con ciertas normas que pueda prescribir la exégesis hermenéutica, sino a algo más simple y básico: leer con fantasía y asombro, con preocupación (caring) hacia los personajes, siendo conmovidos por sus destinos, lo cual es compatible con muchas interpretaciones diferentes. Lo que se excluye es leer con desdén hacia ellos u observarlos como si fueran meras variables de una fórmula fijada de antemano (Nussbaum, 1991, p. 894). Mediante la lectura Nussbaum integra la dimensión de la compasión en la esfera pública, revitalizando y actualizando la figura del "espectador juicioso" de la que hablara Adam Smith.

\subsection{Imaginación literaria e imaginación pública}

Nussbaum considera que ciertas características de la imaginación literaria son rescatables para la configuración de aquello que denomina como imaginación pública, puesto que la literatura supone una vía de incorporación de las emociones a los procesos de deliberación pública. Concibe la imaginación pública como aquella "imaginación que sirva para guiar a los jueces en su juicios, a los legisladores en su labor legislativa, a los políticos cuando midan la calidad de vida de gentes cercanas y lejanas" (Nussbaum, 1991, 879; 1997, 27) y la imaginación literaria como aquella que concede una importancia capital a la ficción narrati- va por sus posibilidades de aplicación práctica, entre otras cosas, servir como método de introspección, de conocimiento de nosotros mismos (Nussbaum, 2005).

Sin embargo para que puedan llevarse a cabo exitosamente los procesos de deliberación pública, estos deben realizarse por sujetos que previamente se han convertido en una clase especial de sujetos: los agentes perceptivos. Por esta razón, la educación ostenta un papel fundamental en todo el proyecto de Nussbaum, puesto que mediante la educación se desarrollan esas habilidades de comprensión y de actitud crítica necesarias para la buena deliberación ética ${ }^{7}$.

La autora posee dos obras sistemáticas sobre la cuestión de la educación en las que señala los elementos fundamentales para la deliberación ética: $E I$ cultivo de la humanidad (Nussbaum, 2005), en la que plantea cuestiones acerca del concreto diseño curricular universitario en clave intercultural, y Sin fines de lucro. Por qué la democracia necesita de las humanidades (Nussbaum, 2010, p. 26) en la que subraya la necesidad de incorporar las artes y humanidades, como fuente de recursos morales, en todo proyecto educativo. La perspectiva que adopta la autora es la propia de un pensamiento cosmopolita, continuando las tesis que sostiene en los Límites del Patriotismo (Nussbaum, 1999) siendo, por tanto, su objetivo la formación de estudiantes que sean a su vez ciudadanos del mundo. La autora considera fundamental la inclusión de los estudios interculturales en los planes de estudio universitarios precisamente porque de este modo es posible descubrir los rasgos de unión de la humanidad y, por tanto, proceder a su cultivo. De este modo, aporta muchas y muy variadas razones para desear la inclusión de cursos interculturales, pero todas ellas descansan en un presupuesto base: la educación de los estudiantes como ciudadanos. Nussbaum ve fundamental esta misión de la Universidad (de Tienda, 2009), ya que entiende que trasciende los estudios de secundaria, puesto que la tarea de educar ciudadanos, además de ser una actividad continua en la vida de una persona, necesita cierto grado de madurez. Estos requisitos son precisados porque la dimensión de la educación de semejante ciudadano no se circunscribe al aprendizaje de normas de civilidad de un contexto local, sino que el ciudadano de Nussbaum es un ciudadano del mundo. De este modo la instrucción de buenos ciudadanos adquiere un tinte cosmopolita de raigambre estoica y pasa a entenderse como el cultivo de la humanidad (Nussbaum, 2005, p. 27). 


\section{CONCLUSIÓN}

Al preguntarnos por los valores y por su efectiva integración en los procesos de deliberación pública y diseño institucional hemos advertido diversas complejidades teóricas que impiden que estos desempeñen un papel efectivo de guía en la esfera pública. Estas dificultades, procedentes de la controversia teórica entre las posiciones objetivistas y las subjetivistas en la conceptualización del valor, obstaculizan la aplicación práctica e inmediata de los valores a este cometido y relegan la cuestión a la previa dilucidación académica acerca de qué es un valor. Por ello, en aras a avanzar en estos objetivos de interés público, en estas páginas se ha sugerido un cambio de perspectiva metodológica. Con el fin de conseguir ulteriores fines prácticos, se ha centrado la cuestión fundamental en determinar el mecanismo humano de captación de los valores, para proceder posteriormente a precisar si este mecanismo se encuentra realmente integrado en los procesos de deliberación pública.

Al constatar que las sociedades están marcadas por la convivencia de una pluralidad de concepciones ético-existenciales, resulta una cuestión compleja la elaboración y fundamentación de un catálogo único y homogéneo de valores sustantivos. Por ello, tras precisar que las emociones son el dispositivo psicofísico con el que cuentan los seres humanos para la captación de los valores, se plantea como necesaria su incorporación en los procesos de deliberación pública, puesto que su utilización práctica supone la vía de acceso inmediata a la esfera de valor y, además, evita el conflicto entre el universalismo y el particularismo.

En este sentido, el método desarrollado por Martha Nussbaum del equilibrio perceptivo permite incorporar las emociones en los procesos éticos deliberativos, mediante un recurso extraordinariamente original: la literatura, ofreciendo importantes posibilidades de aplicación práctica. Una de estas vías de aplicación sería la introducción de los relatos narrativos, tanto históricos como ficcionales, en los planes de estudio universitarios. La inclusión de este tipo de módulos en los programas educativos posibilitaría el ejercicio de la imaginación empática que, además de profundizar en una tarea introspectiva, permite trascender la propia realidad y comprender al otro, no tanto en su cualidad de vecino inmediato, sino como ser humano, independientemente del tiempo y lugar en el que se encuentre. Con ello, la capacidad experiencial y comprensiva del estudiante se vería enriquecida y sería posible llevar a cabo procesos deliberativos que incorporaran las emociones en su propia estructura, como vía de acceso a los valores.

En definitiva, el objetivo de recurrir a la literatura como medio para incorporar los valores a través de las emociones en los procesos de deliberación públi$\mathrm{ca}$, si bien resulta algo extraordinariamente novedoso en el panorama contemporáneo de la filosofía política y del derecho, permite de forma valiosa y fructífera guiar la deliberación ética en torno a lo que realmente importa.

\section{NOTAS}

1 A lo largo de nuestra historia de pensamiento se ha hablado de los valores, peo hasta los siglos XIX y XX no encontramos un tratamiento más sistemático de esta cuestión. Nietzsche fue el autor que puso de manifiesto la importancia fundamental de los valores y las sucesivas transvaloraciones en el devenir histórico, pero es Scheler, influenciado por las tesis de Brentano y la fenomenología de Husserl, el autor que inaugura la teoría de los valores como disciplina con cierta autonomía. La Ética de Scheler supone todo un manual, articulado y sistemático, acerca de los valores, a los cuales confiere una entidad material, pese a presuponerles una estructura normativa formal y por ello considerarlos objetivos.

2 Esta idea es fundamentalmente defendida por Ortega y Gasset a partir de su teoría del perspectivismo epistemológico, por el cual se presupone una verdad omnímoda, tejida por la suma de perspectivas desde las cuales se accede a la verdad. Cfr. Ortega y Gasset (1980).

3 Se alude a las posiciones subjetivistas del primer Meinong (1894) y al subjetivismo propio de los pragmatistas, en especial, la tesis defendida por Perry por la que hace residir el origen y fundamento del valor en el sujeto que valora y en la categoría de interés: cfr. R. B. Perry (1967).

4 Rawls define el "equilibrio reflexivo" en su Teoría de la Justicia como "la hipótesis de que los principios que serían escogidos en la posición original son idénticos a aquellos que corresponden a nuestros juicios madurados y que por tanto estos principios describen nuestro sentido de la justicia" (Rawls, 1993, p. 68). A su vez, en su obra posterior del $\mathrm{Li}$ beralismo político caracteriza esta figu- ra como la formulación de "ideas y principios de un modo lo suficientemente claro como para que combinen entre sí dando lugar a una concepción política de la justicia que congenie con nuestras convicciones más firmes. Expresamos eso diciendo que una concepción política de la justicia, para ser aceptable, tiene que estar de acuerdo con las convicciones que consideramos nuestras, en todos los niveles de generalidad y después de la reflexión debida" (Rawls, 1996, p. 38).

5 Nussbaum, en sus primeras obras, ofrece estudios exhaustivos acerca de los conceptos, categorías y método prác-

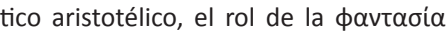
(fantasía), la especificidad del silogismo práctico, el papel cognitivo de las emociones o la dialéctica entre lo particular y lo universal, entre otros. Cfr. Nussbaum (1978). 
6 De hecho la autora distingue entre dos niveles de evaluación moral que se pueden realizar en los textos literarios: a) uno que se refiere al valor ético de la historia que se está narrando; el valor ético que se desprendería sería el propio de la moraleja del texto y b) el nivel, relacionado con la efectiva selección de los textos para un programa educativo

\section{BIBLIOGRAFÍA}

Aristóteles (1999). Ética a Nicómaco. Madrid: Centro de Estudios Políticos y Constitucionales.

Brentano, F. (1874). Psychologie vom empirischen Standpunkt, Leipzig: Duncker \& Humblot.

Crisipo (2006). Testimonios y fragmentos. Madrid: Gredos.

Hartmann, N. (1949). Ethik. Berlin: Walter de Gruyter.

Hume, D. (1998). Tratado de la naturaleza humana, Madrid: Tecnos.

Hutcheson, F. (1728/1971). An essay on the nature and conduct of the passions and affections. Hildesheim: Georg Olms.

James, W. (1884). What is an Emotion? Mind, 19, pp. 188-204.

Meinong, A. (1894). Psychologische ethische Untersuchungen zur Werttheorie. Graz: Leuschner \& Lubensky.

Nussbaum, M. C. (1978). Aristotle's De Motu Animalium. Princeton: Princeton University Press.

Nussbaum, M. C. (1983). Flawed Crystals: James's The Golden Bowl and Literature as Moral Philosophy. New Literary History, 15,1 , pp. 25-50.

Nussbaum, M. C. (1985). Aeschylus and Practical Conflict. Ethics, 95, 2, pp. 233-267.

Nussbaum, M. C. (1986). The fragility of goodness: luck and ethics in Greek tragedy and philosophy. Cambridge: Cambridge University Press. ético, que se dirigiría a preguntarse por los aspectos formales del texto y el bagaje del autor. Cfr. Nussbaum (1995b).

7 Nussbaum sostiene tesis similares en su obra Sin fines de lucro. Por qué la democracia necesita de las humanidades, cuando observa la necesidad del fomento y promoción de tres capacidades

Nussbaum, M. C. (1990). Love's knowledge: essays on philosophy and literature. New York, Oxford: Oxford University Press.

Nussbaum, M. C. (1991). The Literary Imagination in Public Life. New Literary History, 22, 4, pp. 877-910.

Nussbaum, M. C. (1995a). La fragilidad del bien. Madrid: Visor

Nussbaum, M. C. (1995b). Objectification. Philosophy and Public Affairs, 24, 4, pp. 249-291.

Nussbaum, M. C. (1997). Justicia poética: la imaginación literaria y la vida pública. Barcelona: Andrés Bello.

Nussbaum, M. C. (2005). El cultivo de la humanidad: una defensa clásica de la reforma en la educación liberal. Barcelona: Paidós.

Nussbaum, M. C. (2006). El ocultamiento de lo humano: repugnancia, vergüenza y ley. Buenos Aires: Katz.

Nussbaum, M. C. (2008). Paisajes del pensamiento: la inteligencia de las emociones. Barcelona: Paidós Ibérica.

Nussbaum, M. C. (2010). Sin fines de lucro. Por qué la democracia necesita de las humanidades. Madrid: Katz.

Nussbaum, M. C. y Cohen, J. (eds) (1999). Los límites del patriotismo: identidad, pertenencia y "ciudadanía mundial». Barcelona: Paidós Ibérica.

Ortega y Gasset, J. (1980). El tema de nuestro tiempo. Ni vitalismo ni racionalismo. El ocaso de las revoluciones. El sentido básicas, relacionadas con las artes y las humanidades, para garantizar los recursos morales de los que se nutre la democracia: a) la capacidad de pensamiento crítico, b) la capacidad de trascender las lealtades nacionales y enfrentar problemas de alcance internacional y c) la capacidad de desarrollar la imaginación compasiva. Cfr. Nussbaum (2010, p. 26).

histórico de la teoría de Einstein. Madrid: Espasa-Calpe.

Ortega y Gasset, J. (2006). Introducción a una estimativa.- ¿Qué son los valores?. En Obras completas (tomo III (19171925)), Madrid: Taurus, pp. 531-549.

Perry, R. B. (1967). General theory of value: its meaning and basic principles construed in terms of interest. Cambridge: Harvard University Press.

Posner, R. A. (1981). The economics of justice. London: Harvard University Press.

Rawls, J. (1993). Teoría de la justicia. Madrid: Fondo de Cultura Económica.

Rawls, J. (1996). El liberalismo político. Barcelona: Grijalbo Mondadori.

Talavera, P. A. (2006). Derecho y literatura: el reflejo de lo jurídico. Granada: Comares.

Scheler, M. (2000). El formalismo en la ética y la ética material de los valores. Madrid: Caparrós.

Scheler, M. (2001). Ética. Nuevo ensayo de fundamentación de un personalismo ético. Madrid: Caparrós.

Smith, A. (1997). La teoría de los sentimientos morales, Madrid: Alianza Editorial.

Sousa, R. de (1987). The rationality of emotion. Cambridge: MIT Press.

Tienda Palop, L. (2009) La misión de la universidad hoy: una educación intercultural. En Arenas, F. y Gallegos, D. (eds.) El ciudadano democrático: reflexiones éticas para una educación intercultural. Madrid: Plaza y Valdés, pp. 415-432. 